powerful antibiotic is sufficient without type is higher and that of the other types drainage of an abscess." I would like to lower among the offspring in families where question this statement. I have personally the father possesses an A or a B antigen cleared out more than one sterile cavity not present in the mother than in those persisting several months after the apparent families where he does not. This is almost cure of osteomyelitis with antibiotics alone. certainly related to the higher haemoglobin-I am, etc.,

R. MERRYWEATHER

Gloucester

\section{Vitamin D in Patients on Anticonvulsants}

SIR,-Dr. Claus Christiansen and others (23 September, p. 738) showed an increase in bone density during treatment with vitamin $\mathrm{D}$ in 10 epileptic patients on anticonvulsants. We have previously shown significantly lower values of bone density in a group of nine epileptic women compared with a control group of 10 psychiatric patients resident in the same epileptic colony. ${ }^{1}$ After our initial investigation in June 1971 we reinvestigated our groups of patients in February 1972 to find out if there was a seasonal variation in hone density values, but they were unaltered.

During the next six months both groups were given calciferol $50,000 \mathrm{IU} /$ day by mouth. Bone density was assessed by gamma-ray osteodensitometry after three and six months of vitamin $D$ treatment. During vitamin $\mathrm{D}$ treatment no significant alteration in bone density could be demonstrated, but bone density mean values measured both on the heel and elbow remained significantly lower in the group of epileptic patients. None of the patients showed signs of vitamin D overdosage.

The discrepancy between our results and those of Dr. Christiansen and his colleagues might be explained by differences in the epileptics studied with respect to sex, age, duration of anticonvulsant therapy, vitamin $D$ dosage, and calcium intake. We are making further studies of bone density in epileptic patients on anticonvulsants during treatment with vitamin $\mathrm{D}$ and calcium.-We are, etc.,

J. LINDE J. MøLHOLM HANSEN

Medical Department E Frederiksberg Hospital, Copenhagen

K. SIERSB

Department of Epileptic D'seases

V. FuglSANG-FrEDERIKSEN

Department of Psychiatry

The Filadelfia Colony Dianalund, Denmark

\footnotetext{
1 Linde, J., Molholm Hansen, J., Siersbæk-Nielsen, Kournal, 1971, 3, 433.
}

\section{ABO Blood Groups and Abortion}

SIR,-YYur leading article on this subject (11 November, p. 314) has drawn attention to the very considerable number of fetal losses which are related to feto-maternal ABO incompatibility. I wish to draw attention to two other genetic systems besides the ABO system which are involved in the blood-group interaction and which may influence not only the outcome of haemolytic disease of the full-term newborn, but possibly also the incidence of early abortion.

It has been shown ${ }^{1-3}$ in extensive family studies on a wide variety of populations that the frequency of the Hp 1-1 pheno- binding capacity of the plasma of $\mathrm{Hp} 1-1$ individuals than of those of types $\mathrm{Hp} 2-1$ and $\mathrm{Hp} \mathrm{2-2,45}$ which evidently prevents fetal or neonatal death due to haemolysis, either directly by clearing the plasma of haemoglobin or indirectly by conserving iron. It is not clear how far the fetuses saved are those which would otherwise have been subject to early abortion or, on the other hand, those affected by the more classic type of haemolytic disease of late pregnancy and neonatal life. It is therefore desirable that in all investigations of the ABO groups of mothers and fetuses involved in both types of disease or death the haptoglobin types of the mother and father, and if possible that of the fetus, should be determined.

Bottini et al. ${ }^{6}$ have recently shown that in cases where infants have a group $\mathbf{B}$ antigen not possessed by their mothers the proportion of infants with serological signs of haemolytic disease of the newborn is highe in those homozygous for placental alkaline phosphatase gene Plf1 than in those of other types. The effect is not found in cases of group A incompatibility. This effect, be cause of the small numbers so far tested, is less firmly established than that involving the haptoolobins and has been demonstrated only for the classic neonatal type of haemolytic disease. There is therefore a need for further tests on newborn infants, but it is desirable also that tests on aborted fetuses should include an examination of the placental alkaline phosphatase type.

Clarke and his colleagues, ${ }^{7}$ by imitating a natural protective mechanism, have been able to prevent maternal immunization by the $\mathrm{Rh}$ antigen and its sequel, haemolytic disease of the newborn. Perhaps one may hope that an understanding of the protective effects of the haptoglobin and alkaline phosphatase types mentioned may similarly suggest a means of circumventing not only the relatively few deaths which occur as a result of late haemolytic disease due to $A B O$ in compatibility, but also the probably much more numerous early fetal losses due to the same cause.-I am, etc,.

\section{A. E. Mourant}

M.R.C. Serological Population Genetics Laboratory, St. Bartholomew's Hospital,

1 Ritter, H., and Hinkelmann, K., Humangenetik, 2 Kirk, R. L..

Am. L.. Kinns, H., and Morton, N. E.

3 Kirk, R. L., Annals of Human Genetics, 1970/71, 34. 329.

Allison, A. C., and ap Rees, W., British Medical Fournal, 1957, 2, 1137

Giblett, E. R., Genetic Markers in Human Blood. Oxford, B'ackwell, 1969

6 Bottini, E., et al., Vox Sanguinis, 1972, 23, 413 tion of Rh-Hemolytic Disease. Springfield Thomas, 1972.

SIR,-Certain statements in your leading article (11 November, p. 314) on ABO blood groups and spontaneous abortion warrant criticism.

The argument that congenital malformations are a cause of, or are canable of inducing, abortion is surely fallacious. That many abortions, particularly in the early weeks of pregnancy, are abnormal is well known ${ }^{1}$ but the presence of these anomalies cannot be used in a straight cause-and-effect argument. The anomalies are merely a reflection of a total disturbance in the conceptus which subsequently leads to failure of mainenance of an internal environment consistent with the continuance of pregnancy.

My own studies (in preparation) clearly ndicate three major distinct groups of aborted material: (1) those conceptuses with absent or stunted embryos which are associated with gross disturbances of placental structure; (2) those with a severely macerated fetus showing no major malformations and a placenta showing the features of maternal floor infarction ${ }^{2}$; and (3) those with a fresh normal fetus which have apparently been developing normally until abortion.

The mechanisms of abortion in these groups are probably different, though the first two are probably dependent on a progressive decline in placental function while the last is probably related to mechanical factors or an early form of abruption. It would therefore be of interest to know into which group the high incidence of $\mathrm{ABO}$ incompatible fetuses described by Takano and Miller $^{3}$ fell. Their observation does however, suggest that it is probably not safe to argue that $\mathrm{ABO}$ incompatability per se is a cause of abortion but that it is an associated factor which may influence the mode of abortion. Further, it may reflect an increased risk to the abnormally developing or implanted fetus; thus the incompatible fetus has one more factor acting against it in comparison with the compatible fetus. In this respect the term "abnormal development" includes both biochemical and morphological disturbances.

Perhaps of most significance would be the finding that the fetuses in the second group were those most highly related to incompatability, since the aetiology of maternal floor infarction is obscure though it is clearly not the result of infarction of placental tissue. It might represent an unusual form of immunological response in the placenta. This aspect is being further pursued at the present time.

Finally, it must be pointed out that we have as yet no convincing morphological evidence for immunological rejection in human pregnancy, as might be expected in a host-graft reaction.-I am, etc.,

Department of Pathology,

D. I. Rushton Maternity Hospital,

Birmingham
1 Hertig, A. T., in Comparative Asperts of Re-
productive Failure. ed. K. Benirschke, p. 11.
Berlin, Springer-Verlag, 1967.
2 Benirschke, K. and Driscoll, S. G., The Patho-
logy of the Human Placenta, p. 232. New York,
Springer-Verlag, 1967.
3 Takano, K., and Miller, J. R., fournal of
Medical Genetics, 1972, 9, 144.

\section{General Medical Council}

SIR,-In 1958, in response to a stimulus that need not here be described, I read through every volume of the minutes of the G.M.C. from its inception by statute in 1858. Also in that year I attended, as a visitor, a session of the council. These two experiences aroused an interest in the G.M.C. which I shall retain and which prompts me to comment not so much upon your apt editorial (November 18, p. 377) 